\title{
HUMAN 2D EAR BIOMETRIC RECOGNITION BASED ON CONTOUR MATCHING TECHNIQUE
}

\author{
Alagarsamy Santham Bharathy \\ Department of Electronics and Communication Engineering, \\ School of Electronics and Electrical Technology, \\ Kalasalingam Academy of Research and Education, \\ Krishnankoil, Virudhunagar Dt., (India). \\ E-mail: santhembharathy@gmail.com ORCID: https://orcid.org/0000-0003-0978-3905 \\ Kalpana Murugam \\ Department of Electronics and Communication Engineering, \\ School of Electronics and Electrical Technology, \\ Kalasalingam Academy of Research and Education, \\ Krishnankoil, Virudhunagar Dt., (India). \\ E-mail: drmkalpanaece@gmail.com ORCID: https://orcid.org/0000-0002-5121-0468
}

Recepción: 05/12/2019 Aceptación: 03/01/2020 Publicación: 23/03/2020

\section{Gitación sugerida:}

Bharathy, A. S., y Murugam, K. (2020). Human 2D Ear Biometric Recognition Based on Contour Matching Technique. 3C Tecnología. Glosas de innovación aplicadas a la pyme. Edición Especial, Marzo 2020, 207-217. http://doi.org/10.17993/3ctecno.2020.specialissue4.207-217

\section{Suggested citation:}

Bharathy, A. S., \& Murugam, K. (2020). Human 2D Ear Biometric Recognition Based on Contour Matching Technique. 3C Tecnología. Glosas de innovación aplicadas a la pyme. Edición Especial, Marzo 2020 , 207-217. http://doi.org/10.17993/3ctecno.2020.specialissue4.207-217 


\section{ABSTRACT}

This paper presents, the Ear detection biometric is obtainable utilizing normal ear method to detection, which is motivated through normal face acknowledgment methods. This work proposed another ear correlation method dependent on template expansion. The work is connected with ear database given by USTB China on which, the work delivered 100\% exactness more than 180 ear images.

\section{KEYWORDS}

Image Processing, Ear Images, Feature Extraction, Contour Matching. 


\section{INTRODUCTION}

In the recent science technology biometrics where an element is recognized based on physical highlights or conduct qualities (Basit, Javed, \& Anjum, 2005). Physical attributes incorporate unique face, retina, finger, palm print, iris, and ear with so forth while behavioral qualities comprise of step acknowledgment, voice, odour acknowledgment, with mark confirmation. The acquired biometric outcomes are utilizing solo or different methods. The accomplished outcomes show that biometric methods be considerably extra exact with precise over conventional systems. But accuracy, it has been dependably sure issues which stay related to current customary methods. For instance, think about belonging and information. Both can be shared, stolen, overlooked, copied, lost or removed. Anyway, the peril is limited in the event of biometric implies (Moreno, Sanchez, \& Velez, 1999). The biometrics work is amiable within a wide range of safety frameworks. By means of the dangers/progresses of innovations, and it's needed a constant to look at new methods for utilizing like remain solitary relevancies or related to current frameworks. To incorporate any new category of biometric, the state necessary is that it ought to be general, unmistakable, eternal and collectible for example every people should have those highlights (widespread) and highlights ought to recognizable in support of every person (particular). The highlights ought didn't to shift (everlasting) and it must be anything but difficult to get required data from these highlights (collectible) (Jain, Hong, \& Pankati, 2000). Clearly, ears are an unmistakable element of all people making it all around satisfactory. Ear biometrics has a few points of interest over whole face: decreased position able goals, a progressively equal appropriation hue and reduce fluctuation with demeanors and direction of face. In this proposed work, another ear acknowledgment strategy is planned dependent by and large ear; it is connected for individual ID. The remaining of this paper is sorted out as pursues. In section 2 foundation and related work regarding ear acknowledgment are given. Section 3 incorporates pre-handling pursued by highlight origin and coordinating in section 4 . The section 5 test outcomes with talk are accounted for an indefinite section 6 ends be made.

\section{RELATED WORK}

The first ear was utilized for acknowledgments for individual was elaborated in Iannarelli (1989) who utilized labor-intensive methods toward distinguish ear pictures. Tests of 
more than ten thousands ears were concentrated to demonstrate the uniqueness of ears. Arrangement of ear could not modify profoundly after some time. The restorative writing (Victor, Bowyer, \& Sarkar, 2002) gives data that ear development is corresponding later than initial 4 months in birth and modifies are not detectable from the age eight to seventy. In paper, Chang, Bowyer, Sarkar, and Victor (2003), and Chen and Bhanu (2005) utilized Eigen ear image for distinguishing proof. The outcomes got be diverse in the two types. In Kumar (2012), Miyazawa, Ito, Aoki, Kobayashi, and Nakajima (2008), Ito, Iitsuka, and Aoki (2009), Ansari and Gupta (2007), and Hurley, Nixon, and Carter (2005) outcomes demonstrate no distinction in face and ear execution as Victor's outcomes demonstrate that ear execution is more awful over face. As per in Yan and Bowyer (2007), Joshi and Chauhan (2011), Gonzalez, Woods, and Eddins (2004), and Tang (2016), the distinction in result may be because of utilization of various picture quality. As in Kumar (2012), utilized 2D force pictures of ears by means of 3 neural methodologies (Weighted Bayesian, Bayesian, Borda) for acknowledgment. In this work, three pictures of every individual as of 60 individuals were utilized to assess the acknowledgment.

\section{PROPOSED SYSTEM}

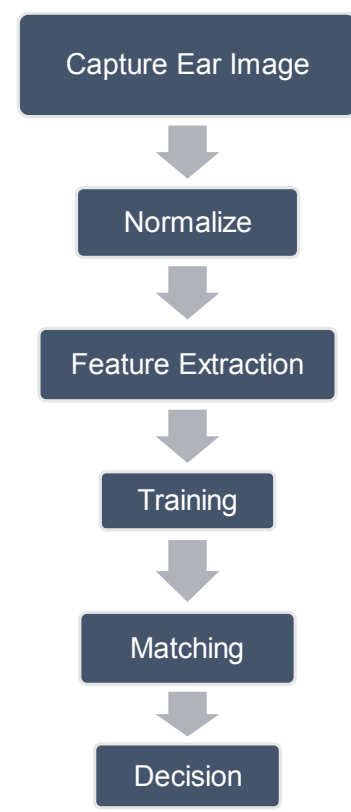

Figure 1. Process. 
Each picture is experienced the accompanying strides before highlight extraction. Ear picture is edited physically from the caught head picture of an individual. Edited ear picture is resized. The hued picture is changed over into grayscale. Concentrate the highlights structure grayscale picture utilizing vigilant edge finder and spare as the paired picture. Manual trimming has been done in the work in light of the fact that robotized ear editing is under the procedure. The sizes of the edited ear picture are extraordinary. So as to locate a similar amount of highlights as of every ear picture, rearranging the pictures to a remarkable fixed size of $80 * 150$ pixels is completed. Every picture is changed over as of color to grayscale. At that point, it is sent in support of the component origin part by the Canny edge finder. In Figure 2 exhibits yield toward finish the pre-handling step. In Figure 2(a) demonstrates the genuine picture in the catalog with the trimmed picture is obvious in Figure 2 (b). Figure 2 (c) and Figure 2 (d) are the resized edited picture with color and grayscale individually. Figure 2 (e) is the genuine element removed after pre-preparing.

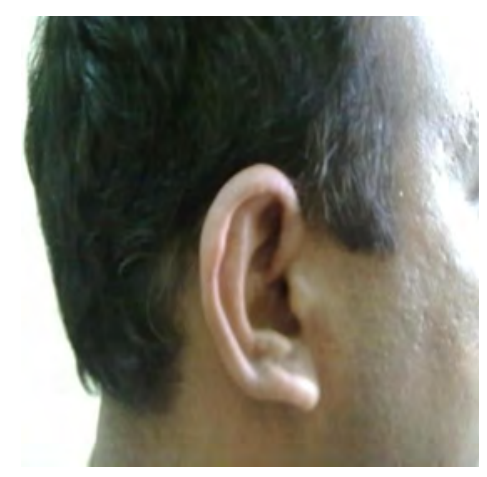

Figure 2 (a). Real Image.

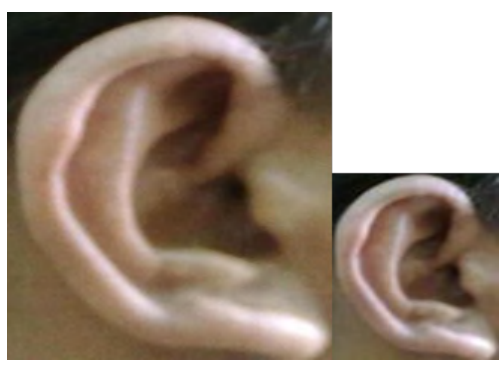

Figure 2 (b). Image Cropped. Figure 2 (c). Image Resized. 


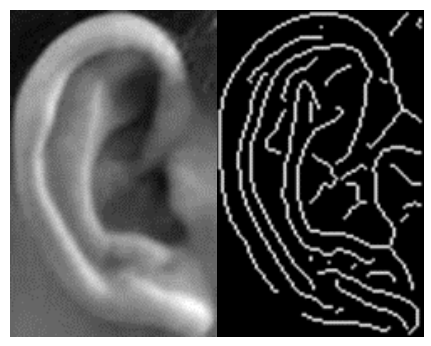

Figure 2 (d). Image Gray Scale. Figure 2 (e). Image Binary with real Features.

\subsection{FEATURE LEVEL EXTRACTION WITH MATCHING}

While the portioned ear can be legitimately utilized during the coordinating stage, most frameworks separate a striking arrangement of highlights to speak to the ear. Highlight extraction alludes to the procedure where the sectioned ear is diminished to a numerical model (e.g., an element vector) that abridges the prejudicial data. In the wake of normalizing the ear pictures, the following stage is including extraction and coordinating. Existing technique vigilant edge finder has been utilized for highlight extraction. Another strategy is proposed for ear correlation dependent by and large ear picture. In this methodology, every ear picture highlights are as a parallel lattice of $80 \times 150$. To build the thickness of ear picture highlights, enlargement activity has been achieved on each ear picture. In Figure $3(\mathrm{a})$ is the real ear picture highlights and $3(\mathrm{~b})$ is the enlarged picture. ' $\mathrm{N}$ ' is a number of the expanded twofold picture of a similar individual with various variety has been utilized to figure normal ear picture. Determined normal ear picture has been spared as a twofold framework for the layout. These exploration works, 180 ear pictures of 60 people (three pictures of every individual) has been utilized. The 3 pictures of every individual have been utilized for normal picture figuring and spare as a double framework of $80 \times 150$ which is utilized as a layout. The ensuing calculation has planned for ear perceiving.

Stage 1: calculate complete number of pixel in twofold normal ear picture format.

Stage 2: achieve bitwise intelligent OR activity among the normal double picture and inquiry picture. Tally yet again the number of resultant.

Stage 3: the all-out number of ones include in Stage 2 is same, which is included in stage 1, at that point show the note ear is perceiving through the personality of layout and outlet. 
Stage 4: if all out no of one's includes in Stage 2 is fewer, at that point and equivalent to the quantity of include in stage 1 in addition to limit esteem (for this situation edge worth is 200 pixels) at that point question ear picture is perceived and exit.

Stage 5: Check on the off chance that it is last normal ear layout, on the off chance that indeed, at that point go to Stage 6 generally go to Step 1 and contrast question picture and another ear format.

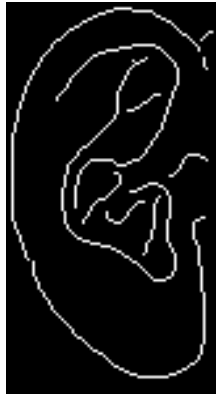

Figure 3 (a). Image in Binary by means of real Features.

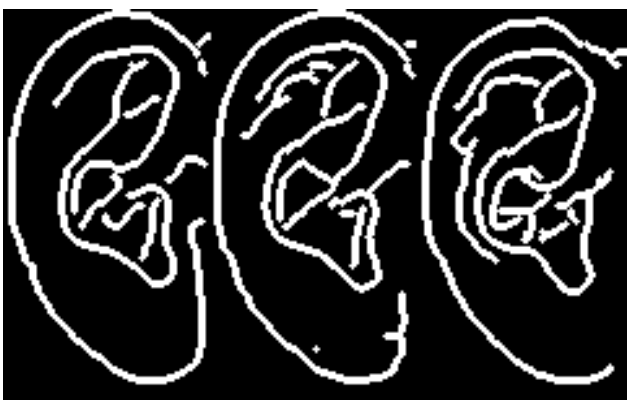

Figure 3 (c). 3 Dilated picture utilized in Average Image Calculation.

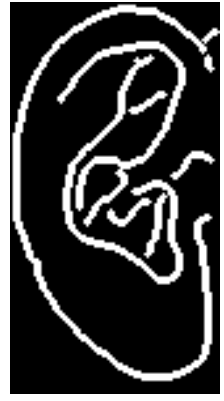

Figure 3 (b). Image Dilated Features.

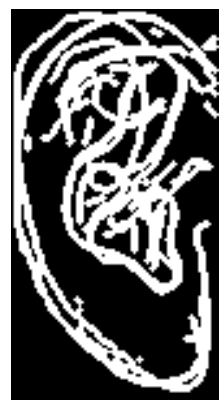

Figure 3 (d). Real Image Average.

\section{RESULTS AND DISCUSSION}

The planned strategy is actualized in MATLAB 2017 version on a laptop. In the examination, ear database from the USTB has been utilized. The databases enclose a sum of 200 pictures with $80 \times 150$ pixels goals. A lot of 60 individuals has been utilized for examinations having at least three pictures each. Three pictures of every individual have been utilized for normal picture computation. The resultant picture has been utilized as a format for ear acknowledgment. 


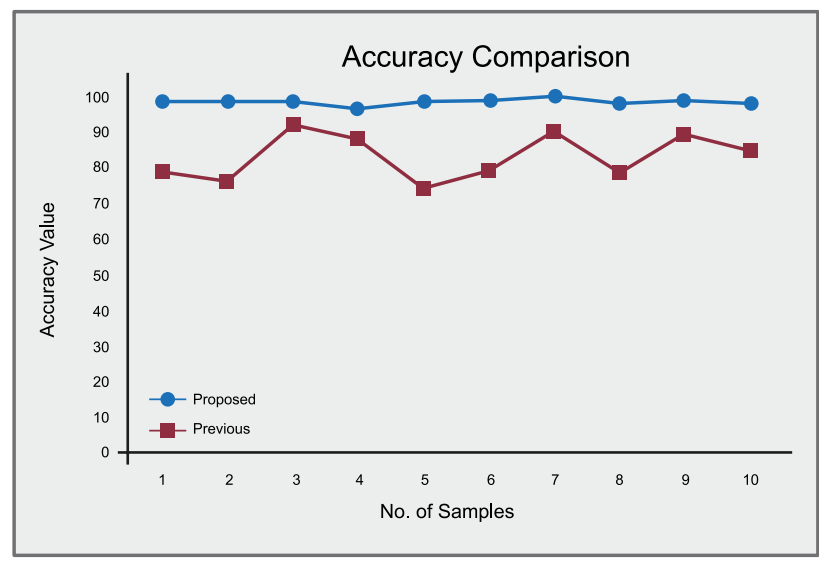

Figure 4. Accuracy comparison Ear Recognition.

Time investigation has demonstrated Figure 4, the time examination among time in second with time taking to perceive explicit ear, at $2.27 \mathrm{GHz}$ Intel 3i processor, inquiry ear picture correlation time and putting away normal ear format is 0.108 Second. In this analysis, 180 ear pictures of 60 people, three pictures of every individual have been utilized for normal picture count. The ear acknowledgment rate is $100 \%$ percent more than 180 pictures. 20 pictures of 20 people, which isn't taking an interest in normal picture computation likewise delivered $90 \%$ exactness by utilizing a limit esteems $\mathrm{TH}=173$. In this examination work, test on possess database is under-preparing, It is normal that as the number of ear picture increment for normal picture computation, the acknowledgment rate will increment.

\section{CONCLUSION}

Ear biometrics got consideration regarding the examination as of late. In this paper, another technique for human acknowledgment is proposed dependent by and large ear pictures. Ear pictures are trimmed physically and resized to a fixed size pursued by the change to grayscale. After that Canny edge identifier is utilized to remove the element from the picture. Database pictures are prepared and put away as a normal ear picture. Results got are promising and empowering with right acknowledgment rate just as the time required. Results will get better if number of ear pictures increment in normal picture count. 


\section{REFERENCES}

Ansari, S., \& Gupta, P. (2007). Localization of ear using outer helix curve of the ear. International Conference on Computing Theory and Applications (ICCTA), pp. 688-692. https://doi.org/10.1109/ICGTA.2007.82

Basit, A., Javed, M. Y., \& Anjum, M. A. (2005). Efficient iris recognition method for human identification. International Scholarly and Scientific Research \& Innovation, 1(4), 2426. https://publications.waset.org/15966/pdf

Chang, K., Bowyer, K. W., Sarkar, S., \& Victor, B. (2003). Comparison and Combination of Ear and Face Images in Appearance-Based Biometrics. IEEE Transactions on Pattern Analysis and Machine Intelligence, 25(9), 1160-1165. https://doi. org/10.1109/TPAMI.2003.1227990

Chen, H., \& Bhanu, B. (2005). Contour Matching for 3D Ear Recognition. Seventh IEEE Workshops on Applications of Computer Vision (WACV/MOTION'05), 1, 123-128. https:/ / doi.org/10.1109/acvmot.2005.38

Gonzalez, G. R., Woods, R. E., \& Eddins, S. L. (2004). Digital Image Processing Using $\operatorname{MATLAB}(R)$. Pearson Education.

Hurley, D. J., Nixon, M. S., \& Carter, J. N. (2005). Force field feature extraction for ear biometrics. Computer Vision and Image Understanding, 98(3), 491-512. https://doi. org/10.1016/j.cviu.2004.11.001

Iannarelli, A. V. (1989). Ear Identification. Paramont Publishing Company.

Ito, K., Iitsuka, S., \& Aoki, T. (2009). A palmprint recognition algorithm using phasebased correspondence matching. In 16 th IEEE International Conference on Image Processing (ICIP). https://doi.org/10.1109/ICIP.2009.5413740

Jain, A., Hong, L., \& Pankati, S. (2000). Biometric Identification. Communications of the ACM, 43(2), 91-98. https://doi.org/10.1145/328236.328110 
Joshi, K., \& Chauhan, N. C. (2011). A Template Matching and Support Vector Machine based Approach for Human Ear Detection and Varification. International Conference on Information, Signal and Communication. https://www.researchgate.net/ publication/281741782_A_Template_Matching_and_Support_Vector_Machine_ Based_Approach_for_Human_Ear_Detection_and_Verification

Kumar, A. (2012). Can We Use Minor Finger Knuckle Images to Identify Humans? IEEE Fifth International Conference on Biometrics: Theory, Applications and Systems (BTAS), pp. 5560. https://doi.org/10.1109/crprw.2014.21

Miyazawa, K., Ito, K., Aoki, T., Kobayashi, K., \& Nakajima, H. (2008). An Effective Approach for Iris Recognition Using Phase-Based Image Matching. IEEE transactions on pattern analysis and machine intelligence, 30(10), 1741-1756. https://doi.org/10.1109/ TPAMI.2007.70833

Moreno, B., Sanchez, A., \& Velez, J. F. (1999). On the Use of Outer Ear Images for Personal Identification in Security Applications. Proceedings IEEE 33rd Annual 1999 International Carnahan Conference on Security Technology (Cat. No.99CH36303). https:/ / doi. org/10.1109/CCST.1999.797956

Tang, T. (2016). Biometric Recognition Using Wavelet Domain Features. Electrical and Electronics Engineering An International Fournal (ELELFU), 5.

Victor, B., Bowyer, K., \& Sarkar, S. (2002). An Evaluation of Face and Ear Biometrics. Proceedings 16th International Conference Pattern Recognition, pp. 429-432. https://doi. org/10.1109/ICPR.2002.1044746

Yan, P., \& Bowyer, K. W. (2007). Biometric recognition using 3D ear shape. IEEE Transactions on Pattern Analysis and Machine Intelligence, 29(8), 1297-1308. https://doi. org/10.1109/TPAMI.2007.1067 
